\title{
Difference in haemodynamic microenvironment in vessels scaffolded with Absorb BVS and Mirage BRMS: insights from a preclinical endothelial shear stress study
}

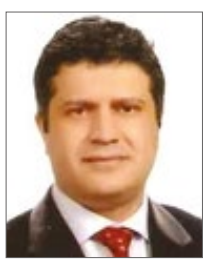

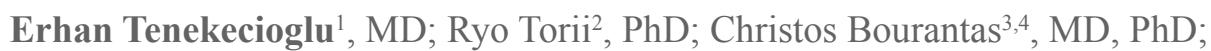

Yohei Sotomi ${ }^{5}, \mathrm{MD}$; Rafael Cavalcante ${ }^{1}, \mathrm{MD}, \mathrm{PhD}$; Yaping Zeng ${ }^{1}, \mathrm{MD}, \mathrm{PhD}$; Carlos Collet ${ }^{5}$, MD; Tom Crake 3 , MD; Pannipa Suwannasom ${ }^{1,5}, \mathrm{MD}$; Yoshinobu Onuma ${ }^{1,6}, \mathrm{MD}, \mathrm{PhD}$; Patrick W. Serruys ${ }^{1,7 *}, \mathrm{MD}, \mathrm{PhD}$

1. Department of Interventional Cardiology, Erasmus University Medical Center, Thoraxcenter, Rotterdam, the Netherlands; 2. Department of Mechanical Engineering, University College London, London, United Kingdom; 3. Barts Heart Centre, Barts Health NHS Trust, London, United Kingdom; 4. Department of Cardiovascular Sciences, University College London, London, United Kingdom; 5. Department of Cardiology, Academic Medical Center, University of Amsterdam, Amsterdam, the Netherlands; 6. Cardialysis, Rotterdam, the Netherlands; 7. Imperial College, London, United Kingdom

E. Tenekecioglu and $R$. Torii contributed equally to this manuscript.

GUEST EDITOR: Lorenz Räber, MD, PhD; Cardiology Department, Bern University Hospital, Bern, Switzerland This paper also includes supplementary data published online at: http://www.pcronline.com/eurointervention/126th_issue/210

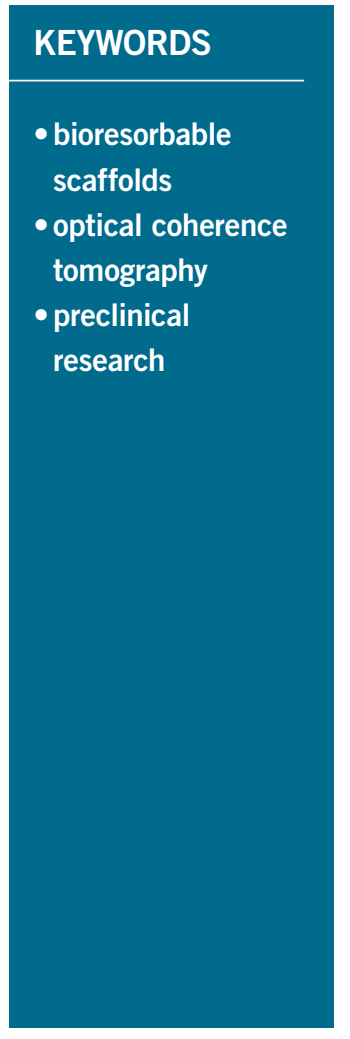

\begin{abstract}
Aims: In silico studies have provided robust evidence that stent design affects local haemodynamic forces, which appear as a major determinant of clinical outcomes following stent implantation. However, the implications of different stent/scaffold configurations on local haemodynamic forces have not yet been investigated in vivo in a comparative fashion. The aim of this study was to compare the ESS distribution in two differently shaped scaffolds using OCT-based modelling.
\end{abstract}

Methods and results: Eight healthy mini pigs were implanted with six Absorb everolimus-eluting bioresorbable vascular scaffolds (Absorb BVS) and five Mirage sirolimus-eluting bioresorbable microfibre scaffolds (Mirage BRMS). Optical coherence tomography (OCT) was performed and strut protrusion was assessed post scaffold implantation. Following the reconstruction of coronary anatomy, blood flow simulation was performed and endothelial shear stress (ESS) was estimated on top of the struts and at luminal surface between the struts in each scaffold. The thicker struts in Absorb $(152 \pm 140 \mu \mathrm{m})$ resulted in an increased protruded distance compared to Mirage $(117 \pm 123 \mu \mathrm{m})(\mathrm{p}=0.003)$. This had an effect on the local haemodynamic microenvironment. ESS at the top of the struts was higher in Absorb (1.69 $\pm 1.20 \mathrm{~Pa})$ than in Mirage $(1.53 \pm 0.91 \mathrm{~Pa})(\mathrm{p}<0.001)$, but lower at inter-strut zones $(0.60 \pm 0.51 \mathrm{~Pa}$ vs. $0.63 \pm 0.50 \mathrm{~Pa}$; $\mathrm{p}<0.01)$ compared to Mirage. Both scaffold types revealed comparable percentages of vessel luminal surface exposed to recirculation.

Conclusions: Absorb demonstrated higher shear stress on top of the struts compared to Mirage. However, in the inter-strut zones shear stress was higher in Mirage than in Absorb. Further research is required to examine the potential value of in vivo computational modelling in optimising scaffold configuration and clinical outcomes.

\footnotetext{
*Corresponding author: Cardiovascular Science Division of the NHLI within Imperial College of Science, Technology and Medicine, South Kensington Campus, London, SW7 2AZ, United Kingdom. E-mail: patrick.w.j.c.serruys@gmail.com
} 


\section{Abbreviations}

Absorb BVS Absorb everolimus-eluting bioresorbable vascular scaffold(s)

ESS endothelial shear stress

Mirage BRMS Mirage sirolimus-eluting bioresorbable microfibre scaffold(s)

OCT optical coherence tomography

PCI

PDLLA

PLLA percutaneous coronary intervention

\section{Introduction}

Local coronary haemodynamic forces, particularly endothelial shear stress (ESS), appear to regulate vessel wall response following implantation of metallic stents or bioresorbable scaffolds (BRS). Numerous in vivo studies implemented intravascular ultrasound (IVUS)-based modelling to examine the association between neointimal hyperplasia and ESS and demonstrated an inverse association between ESS and neointimal growth in bare metal stents ${ }^{1}$, while in drug-eluting stents this association appears to be regulated by the antiproliferative drug ${ }^{2}$. Traditionally, coronary reconstruction performed with IVUS has limited resolution and does not allow detailed assessment of lumen morphology, especially in stented segments. Recent reports implementing optical coherence tomography-based modelling have provided further insights into the implications of scaffold implantation on the local haemodynamic microenvironment, enabling for the first time in vivo evaluation of the effect of the protruded struts on the local haemodynamic patterns ${ }^{3,4}$.

Absorb everolimus-eluting bioresorbable vascular scaffolds (Absorb $^{\text {TM }}$ BVS; Abbott Vascular, Santa Clara, CA, USA) and Mirage sirolimus-eluting bioresorbable microfibre scaffolds (Mirage BRMS; Manli Cardiology, Singapore) have substantial differences in strut thickness, geometrical features and strut connector alignment which, as has been shown in in silico studies, determine flow characteristics and ESS distribution. The aim of this study was to compare the ESS distribution in two differently shaped scaffolds using OCT-based modelling.

\section{Methods}

We analysed data from Yucatan mini pigs implanted with Absorb and Mirage scaffolds (Figure 1). Eight Yucatan mini pigs with healthy coronaries underwent percutaneous coronary intervention (PCI) in the three epicardial coronary arteries via the femoral access according to standard procedures ${ }^{5}$. Six coronary arteries were implanted with a single Absorb and five with a Mirage. The treated coronary arteries were studied by OCT imaging immediately after scaffold implantation. Protocol approval for the animal study was obtained from the Institutional Animal Care and Use Committee and the study was conducted in accordance with the American Heart Association guidelines for preclinical research and the Guide for the Care and Use of Laboratory Animals ${ }^{6}$.

\section{SCAFFOLD DESIGN}

The Absorb BVS is made of poly L-lactic acid (PLLA), coated with a layer of a 1:1 mixture of an amorphous matrix of poly $\mathrm{D}$, L-lactic acid (PDLLA), and elutes everolimus $\left(8.2 \mu \mathrm{g} / \mathrm{mm}^{2}\right)$. The Absorb is manufactured using extrusion and laser machining techniques, has a strut thickness of $157 \mu \mathrm{m}$ and is designed with inphase zig-zag hoops linked with bridges.

The Mirage is made of PDLLA, of which D (dextrorotatory)isomer constitutes $<5 \%$ of the total polylactic acid (PLA), is coated with a biodegradable PLA and elutes sirolimus. The Mirage is manufactured by winding the polylactide monofilaments into a helix-coiled structure attached by longitudinal spine microfibres. The struts have a circular shape and a thickness of $125 \mu \mathrm{m}$ (Figure 1). The helical-coil design is fastened by longitudinal spine microfibres which provide radial strength to the device $(148.54 \mathrm{kPa})$ that is similar to the Absorb $(148.00 \mathrm{kPa})^{7}$.

\section{DATA ACQUISITION}

$\mathrm{X}$-ray angiography was performed using the HiCor cardiac angiography system (Siemens, Erlangen, Germany). OCT was performed
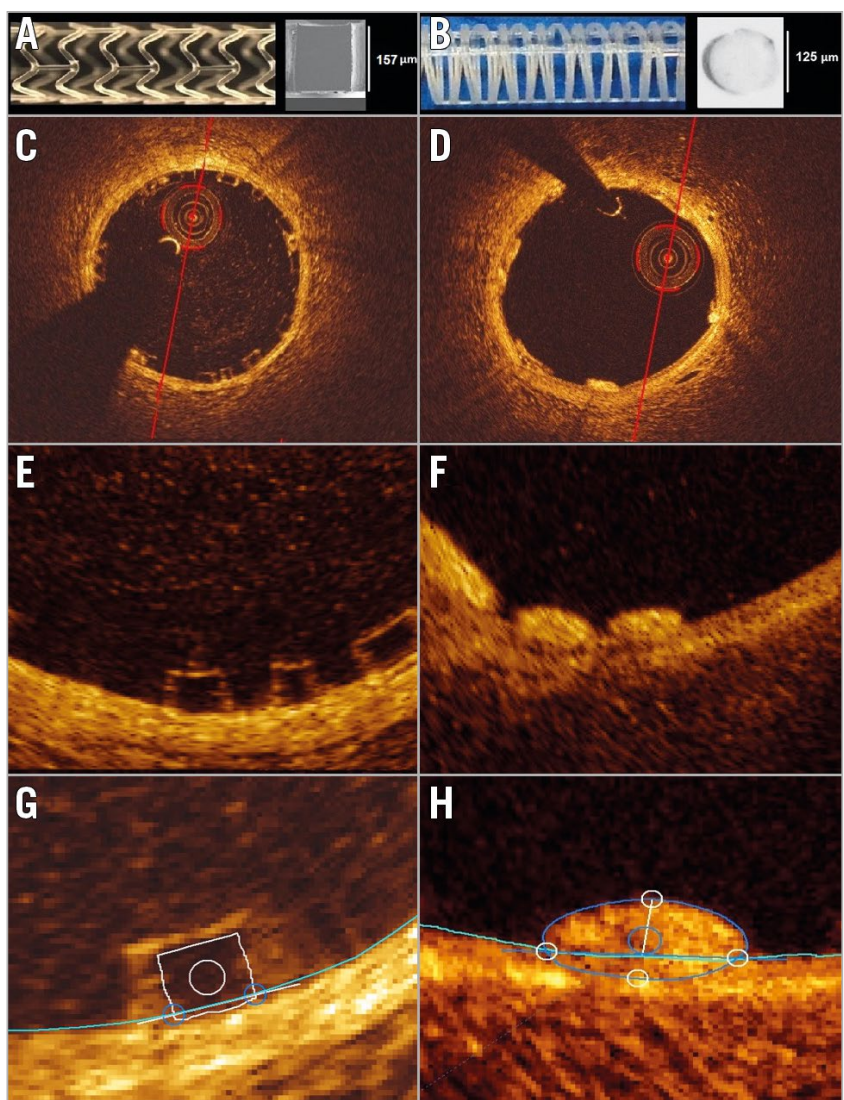

Figure 1. General characteristics of Absorb BVS and Mirage BRMS. Absorb BVS 1.1 and cross-section of an Absorb BVS strut (A). Mirage BRMS and cross-section of a Mirage BRMS strut (B). The strut of the Absorb has a translucent rectangular shape $(C, E)$, whereas the strut of the Mirage is circular, non-translucent $(D, F)$ and protrudes less in the lumen of the vessel. Representation of the protrusion analysis in Absorb $(G)$ and Mirage $(H)$. 
following scaffold implantation in all treated coronary arteries. The scaffolded segments were assessed using a C8-XR OCT System (St. Jude Medical, St. Paul, MN, USA) that was pulled back at a speed of $18 \mathrm{~mm} / \mathrm{sec}$. A non-occlusive flushing technique was used for blood clearance by injection of contrast media. The acquired data were stored in DICOM format and transferred to a workstation for further analysis.

\section{PROTRUSION ANALYSES}

The protrusion analyses on OCT were performed using a special version of QCU-CMS software (version 4.69; Leiden University Medical Center, Leiden, the Netherlands). The analysis on OCT was performed in the scaffolded segment at every $100 \mu \mathrm{m}$ using a previously presented methodology ${ }^{8}$ (Figure 1). The details of protrusion analyses can be found in the Supplementary Appendix.

\section{CORONARY ARTERY RECONSTRUCTION}

Coronary artery reconstruction was performed using a well-established and validated methodology 9 . Two reconstructions were performed for each scaffold and proximal/distal non-scaffolded segments, one from the flow area borders (flow model) in both scaffolded and non-scaffolded segments, and the other from the flow area in the non-scaffolded segment and the lumen area in the scaffolded segment (reference model) (Figure 2A, Figure 2B). The details of 3D coronary artery reconstruction can be found in the Supplementary Appendix.

\section{BLOOD FLOW SIMULATION}

The flow models were processed with computational fluid dynamic (CFD) techniques. A finite volume mesh was generated and then blood flow simulation was performed and the ESS was estimated by solving the 3D Navier-Stokes equations (ANSYS ${ }^{\circledR}$ FLUENT $^{\circledR}$; ANSYS Inc., Canonsburg, PA, USA) ${ }^{10}$. The ESS was measured at the top of the strut and at the luminal surface between the struts in the scaffolded segment and along the axial direction per $0.2 \mathrm{~mm}$ interval with the use of an in-house algorithm (Figure 3 ). The details of 3D coronary artery reconstruction can be found in the Supplementary Appendix.

\section{STATISTICAL ANALYSIS}

Continuous variables were tested for normality with the Kolmogorov-Smirnov test and are presented as mean \pm SD or median (interquartile range) as appropriate. Categorical variables are presented as counts and percentages. Continuous variables were compared by the Kruskal-Wallis test or Mann-Whitney U test. Categorical variables were compared by the Pearson chi-square test. A p-value $<0.05$ was considered statistically significant.

As the data in the study have multilevel structure and unbalanced design, mixed effects models were used for statistical analysis. To compare the ESS values in different scaffold groups, the multilevel model was initially built with fixed effects on scaffold type, cross-sectional area and interaction of the scaffold type with cross-sectional area and random effects on animal ID, scaffold type and cross-section ID. After comparing different models using maximum likelihood, the best fitted model was selected.

In the protrusion analysis, animal and device types were implemented as random effects, while post-dilatation pressure was input into the model as a fixed effect.

Reproducibility of protrusion analysis for Absorb was previously reported by Sotomi et $\mathrm{al}^{8}$. In the present study, reproducibility of the protrusion analysis for Mirage was assessed with the interclass correlation coefficient (ICC) for absolute agreement (ICCa) with its $95 \%$ confidence intervals (CI) using 100 randomly selected Mirage struts 8 . Analyses were carried out using the statistical analysis programme SPSS, Version 21 (IBM Corp., Armonk, NY, USA), R V. 3.2.3 and the R package lme4 (R Foundation for Statistical Computing, Vienna, Austria) ${ }^{11}$.

\section{Results}

One left anterior descending (LAD) coronary artery, three left circumflex (LCx) and two right coronary arteries (RCA) were implanted with an Absorb, and two LAD, one LCx and two RCA with a Mirage. Scaffold dimensions and procedural parameters are shown in Supplementary Table 1. The dimensions of the proximal edge segment, of the scaffolded segment and of the distal edge segment are shown in Table 1.

\section{PROTRUSION ANALYSIS}

The protrusion analyses were performed at cross-section and at device level. In cross-section level analysis, there was a significant difference between the scaffolds in the protrusion distances $(152 \pm 140 \mu \mathrm{m}$ for Absorb, $117 \pm 123 \mu \mathrm{m}$ for Mirage; $\mathrm{p}=0.003)$, a fact that should be attributed to the different strut thicknesses. The results in the device level analysis were similar. The protrusion distances were significantly increased in the Absorb compared to the Mirage $(152 \pm 12.2 \mu \mathrm{m}$ vs. $116 \pm 11.1 \mu \mathrm{m} ; \mathrm{p}<0.0001)$. The interobserver reproducibility (ICCa 0.884, CI: 0.827-0.922) and the intra-observer reproducibility (ICCa $0.782, \mathrm{CI}: 0.675-0.854$ ) for the protrusion distances indicated good agreement in the Mirage.

\section{ENDOTHELIAL SHEAR STRESS ANALYSIS}

There were several layers of grouping within the data of the study: eight animals (level 3) received scaffold implants in their coronary arteries, and different types of scaffold were used in different vessels within the same animal. Each scaffolded segment had several crosssections (level 2) and in each cross-section (level 1) the ESS was measured on the top of the struts and at the luminal surface between the struts. After setting the model with random and fixed effects variables, multilevel linear regression analysis revealed that the Absorb had significantly higher ESS at the top of the struts compared to the Mirage. In the luminal surface in the areas between the struts, the Mirage revealed higher ESS compared to the Absorb. On top of the struts the ESS in Absorb was $1.69 \pm 1.20 \mathrm{~Pa}$, and $1.53 \pm 0.91 \mathrm{~Pa}$ in the Mirage $(p<0.001)$, while in the areas between struts the mean ESS values were $0.60 \pm 0.51 \mathrm{~Pa}$ and $0.63 \pm 0.50 \mathrm{~Pa}$, respectively $(\mathrm{p}<0.001)$ (Table 2); $52 \%$ of the scaffolded surface in the Absorb and $47 \%$ in 


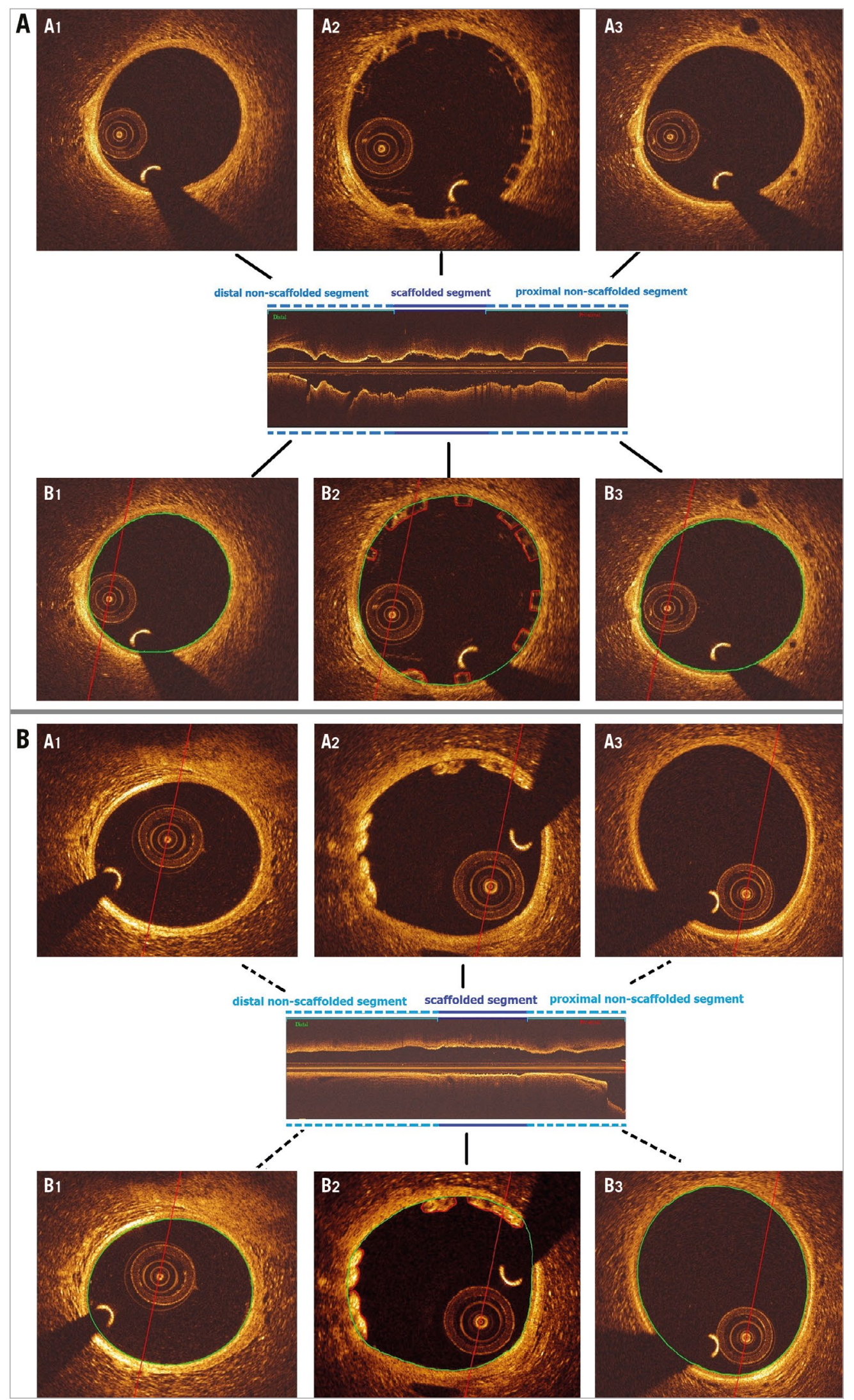

Figure 2. Contour notation methodology in scaffolded and non-scaffolded vessel segments in Absorb BVS (A) and Mirage BRMS (B). In the non-scaffolded and scaffolded segments, the observer delineated the flow area-defined in the non-scaffolded segment by the lumen border (Figure 2A, panels B1 and B3; Figure 2B, panels B1 and B3) and in the scaffolded segment by the adluminal side of the struts and by the lumen border in the areas between the struts (Figure 2A, panel B2; Figure 2B, panel B2). 
Table 1. OCT analysis of scaffolded and non-scaffolded segments according to the scaffold type (device level).

\begin{tabular}{|c|c|c|c|}
\hline & Absorb BVS $(n=6)$ & Mirage BRMS $(n=5)$ & $p$-value \\
\hline Scaffolded segment lumen area $\left(\mathrm{mm}^{2}\right)$ & $7.57(7.11-7.78)$ & $6.35(3.49-9.21)$ & 0.22 \\
\hline Distal non-scaffolded segment lumen area $\left(\mathrm{mm}^{2}\right)$ & $4.97(4.25-5.81)$ & $5.14(2.01-8.27)$ & 0.26 \\
\hline Proximal non-scaffolded segment lumen area $\left(\mathrm{mm}^{2}\right)$ & $6.34(6.06-9.74)$ & $5.58(4.69-6.47)$ & 0.49 \\
\hline Strut area $\left(\mathrm{mm}^{2}\right)$ & $0.22(0.20-0.23)$ & $0.63(0.22-1.04)$ & $<0.001$ \\
\hline
\end{tabular}

\begin{tabular}{|c|c|c|c|c|}
\hline Scaffold & Animal & $\begin{array}{l}\text { Median lumen area }(Q 1-Q 3)- \\
\text { scaffolded segment }\left(\mathrm{mm}^{2}\right)\end{array}$ & $\begin{array}{c}\text { Median lumen area (Q1-Q3) - distal } \\
\text { non-scaffolded segment }\left(\mathrm{mm}^{2}\right)\end{array}$ & $\begin{array}{l}\text { Median lumen area (Q1-Q3) - proximal } \\
\left.\text { non-scaffolded segment ( } \mathrm{mm}^{2}\right)\end{array}$ \\
\hline Absorb BVS-1 & A & $8.0(6.94-8.36)$ & $3.48(3.38-3.61)$ & $5.62(5.17-6.68)$ \\
\hline Absorb BVS-2 & B & $8.38(7.93-8.71)$ & $4.11(3.94-4.41)$ & $6.17(5.32-6.38)$ \\
\hline Absorb BVS-3 & $C$ & $6.92(6.81-7.14)$ & $5.04(4.11-5.15)$ & 6.04 (4.89-7.05) \\
\hline Absorb BVS-4 & D & $8.69(8.55-8.93)$ & $4.78(4.52-5.10)$ & $7.75(7.57-8.09)$ \\
\hline Absorb BVS-5 & $E$ & $7.96(7.70-8.36)$ & $7.37(6.72-7.89)$ & $12.63(11.14-14.24)$ \\
\hline Absorb BVS-6 & $\mathrm{F}$ & $7.42(7.24-7.51)$ & $5.01(4.21-7.23)$ & $6.11(5.68-6.41)$ \\
\hline Mirage BRMS-1 & $\mathrm{F}$ & $7.02(6.88-7.11)$ & $4.37(4.26-4.47)$ & $4.58(4.21-4.72)$ \\
\hline Mirage BRMS-2 & $\mathrm{F}$ & $5.78(5.66-5.92)$ & $5.14(4.50-5.69)$ & $5.79(3.94-8.52)$ \\
\hline Mirage BRMS-3 & G & $8.98(8.29-9.81)$ & 7.40 (4.59-7.95) & $5.75(5.59-6.12)$ \\
\hline Mirage BRMS-4 & A & 7.25 (7.04-7.78) & 4.57 (4.39-7.05) & $5.18(4.74-5.44)$ \\
\hline Mirage BRMS-5 & $\mathrm{H}$ & $7.13(7.08-7.35)$ & $7.80(7.42-7.95)$ & $5.58(5.45-5.81)$ \\
\hline
\end{tabular}

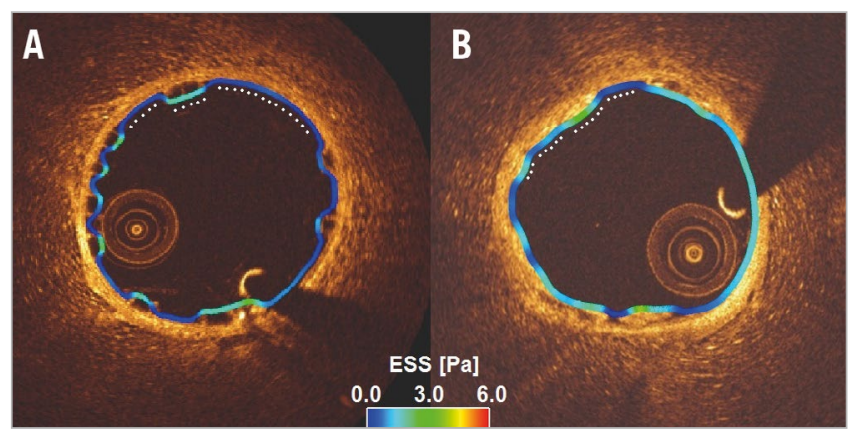

Figure 3. Shear stress quantification methodology. Shear stress is analysed at the top of the struts and in the inter-strut areas separately at each circumferential $1^{\circ}$ angle in each cross-section. The white dots depict circumferential $1^{\circ}$ angle location. A) Absorb BVS. B) Mirage BRMS.

the Mirage $(125 \mu \mathrm{m})$ was exposed to a low $(<1 \mathrm{~Pa})$ athero-promoting ESS environment ( $p<0.0001$ ) (Figure 4). Lumen cross-sectional area also had an effect on ESS. Increase in the cross-sectional area resulted in a significant decrease in ESS both at the top of the struts and at inter-strut zones $(\mathrm{p}<0.001$ for the ESS on top of the struts, $\mathrm{p}<0.001$ for inter-strut ESS). The maximum and mean shear rates and the percentage volumes of the scaffolded segments exposed to shear rates $>500 \mathrm{~s}^{-1}$ and $>1,000 \mathrm{~s}^{-1}$ were numerically higher in Absorb than in Mirage; nevertheless, these differences did not reach statistical significance (Table 3, Figure 5). Similarly, the percentage of the recirculation areas was numerically higher in the Absorb, but again this difference did not reach statistical significance (3.26 \pm 2.07 vs. 2.71 $\pm 1.32 ; \mathrm{p}=0.87$ ) (Supplementary Table 2, Figure 6).

\section{Discussion}

In this study, we evaluated two different types of BRS with different strut geometries, thicknesses, and strut connector alignment in a porcine coronary artery model. The findings can be summarised as follows. 1) The protrusion distances were higher in Absorb, a fact that should be attributed to the increased strut thickness of this scaffold. This difference resulted in 2) increased ESS at the top of the strut in this device, 3) lower ESS in the areas between the struts compared to the Mirage, 4) numerically higher percentage volumes exposed to high shear rates, and 5) increased recirculation areas in Absorb. These differences, however, did not reach statistical significance for recirculation area and shear rate.

Numerous in silico studies have demonstrated that stent/scaffold design affects the local haemodynamic forces following

Table 2. Endothelial shear stress (ESS) values at the top of the struts and between the struts in the scaffold groups.

\begin{tabular}{|l|c|c|c|}
\hline \multicolumn{1}{|c|}{ Scaffold } & Absorb BVS & Mirage BRMS & p-value* \\
\hline Strut-top ESS (Pa) & $1.69 \pm 1.20$ & $1.53 \pm 0.91$ & $<0.001$ \\
\hline Inter-strut ESS $(\mathrm{Pa})$ & $0.60 \pm 0.51$ & $0.63 \pm 0.50$ & $<0.001$ \\
\hline${ }^{*} p$-values come from linear mixed effects analysis. & \\
\hline
\end{tabular}




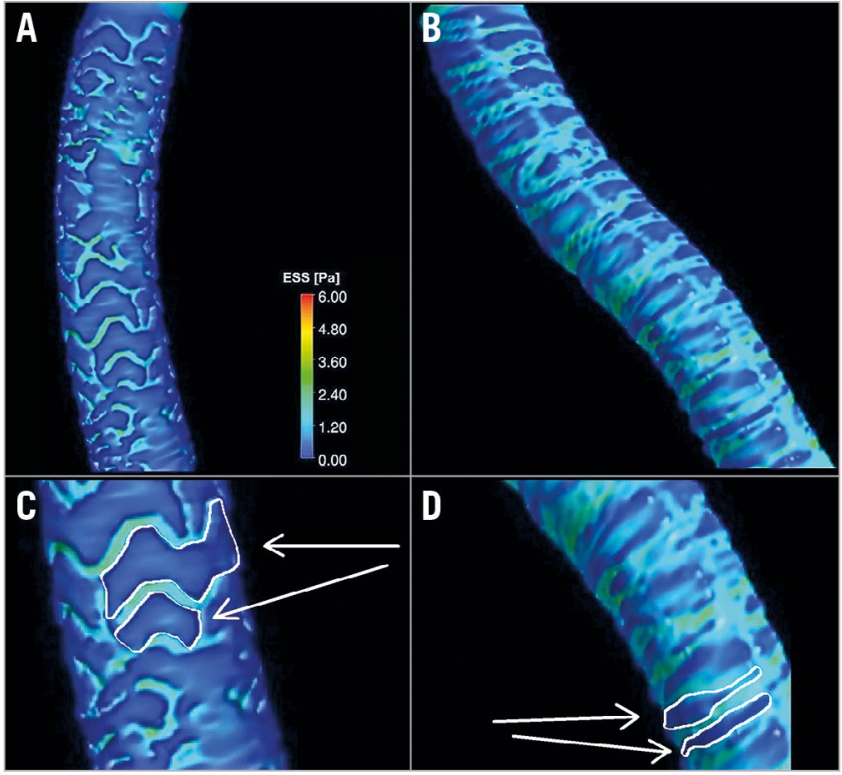

Figure 4. Three-dimensional reconstruction of scaffolded coronary anatomy from the fusion of coronary angiograms and OCT data with the local ESS being portrayed in a colour-coded map (dark blue indicates low ESS $<1.0 \mathrm{~Pa}$ and aquamarine demonstrates ESS $\geq 1.0$ Pa). A) \& C) Absorb. B) \& D) Mirage. Note the larger dark blue area in Absorb (C).

implantation ${ }^{12,13}$. The strut shape, strut thickness, maximal coil pitch distance and strut alignment with regard to coronary flow as well as the alignment of the strut connectors appear to determine the local flow patterns ${ }^{13}$. More importantly, the differences in the local haemodynamic profile following stent/scaffold configuration appear to determine clinical outcomes after PCI. In the bare metal stent era, it was shown that stents with thinner struts were associated with a lower incidence of in-stent restenosis and better clinical outcomes, while in DES the implications of stent configuration on clinical outcomes were suppressed by the antiproliferative drug ${ }^{14-16}$. In the BRS era, however, there has been a paradigm shift. Recent registry and meta-analysis studies have revealed an increased incidence of stent thrombosis following BRS implan$\operatorname{tation}^{17,18}$. These alarming findings have been attributed to the suboptimal local haemodynamics induced by the thick rectangular-shaped struts and scaffold underexpansion; efforts are currently being made to optimise scaffold design.

In silico studies may be helpful in assessing the effect of stent/ scaffold design on ESS in treated segments, but they have significant limitations. First, they assume that the stent struts are well apposed. Reports have shown that this is not the case in the clinical setting where up to $30 \%$ of the struts are embedded into the vessel wall ${ }^{19}$. In addition, they assume that the stent/scaffold is fully deployed in the treated vessel and thus they are unable to assess the implications of stent/scaffold underexpansion or early recoil on the ESS distribution ${ }^{20}$. Finally, they do not take into account the vessel curvature and the changes in vessel geometry induced during device implantation, which depend on vessel curvature and on the mechanical properties of the deployed device, and appear to affect the local haemodynamic forces ${ }^{21}$.

Taking into account these limitations, we examined for the first time in vivo, in an animal model, the implications of two different scaffold designs with different configuration on the local flow patterns. We found higher ESS on the top of the struts in Absorb compared to the Mirage. Absorb has thicker rectangular-shaped struts which, as has been shown in previous experimental and in silico

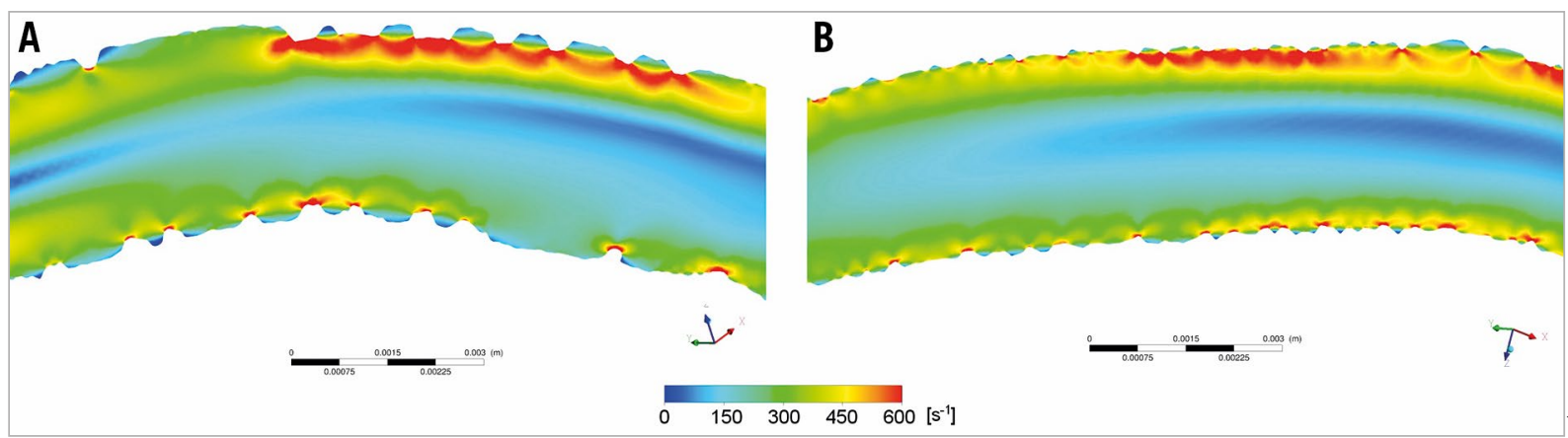

Figure 5. Increased shear rate at the top of the struts in the Absorb and Mirage scaffolds. A) Absorb. B) Mirage.

Table 3. Shear rate analysis results in the scaffolded segments in both types of scaffold.

\begin{tabular}{|c|c|c|c|}
\hline & Absorb BVS & Mirage BRMS & $p$-value \\
\hline Maximum shear rate $\left(\mathrm{s}^{-1}\right)$ & $2,060 \pm 1,778$ & $1,621 \pm 755$ & 0.58 \\
\hline Mean shear rate $\left(\mathrm{s}^{-1}\right)$ & $238 \pm 133$ & $234 \pm 67$ & 0.95 \\
\hline Percentage volume exposed to shear rate $>500 \mathrm{~s}^{-1}(\%)$ & $7.6 \pm 16$ & $1.1 \pm 2.7$ & 0.59 \\
\hline Percentage volume exposed to shear rate $>1,000 \mathrm{~s}^{-1}(\%)$ & $3.7 \pm 5.7$ & $0.09 \pm 0.25$ & 0.39 \\
\hline
\end{tabular}




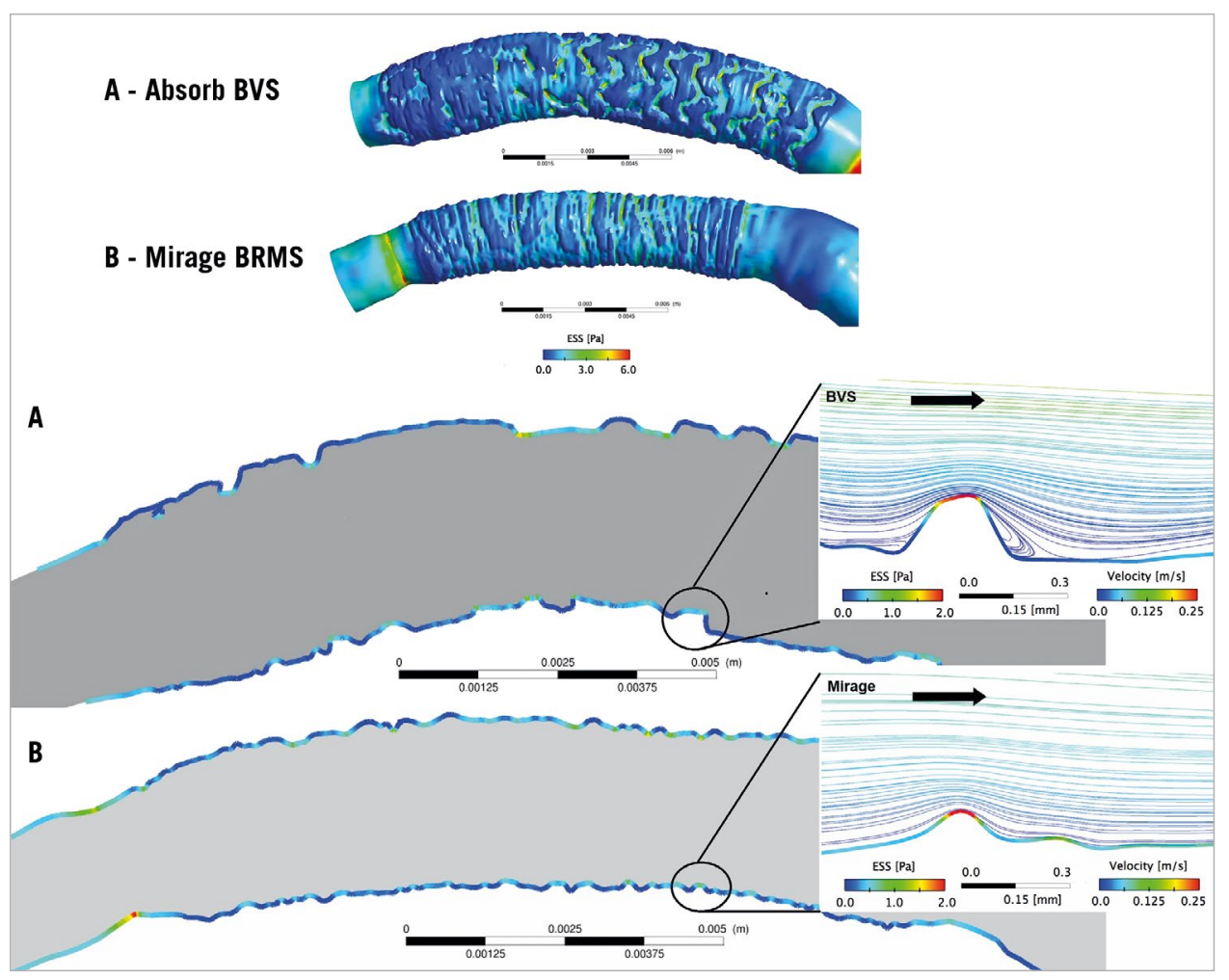

Figure 6. Blood flow streamlines with velocity and ESS colour-coded bars for the Absorb and Mirage. ESS values are high on top of the strut. Low ESS is noted between the Absorb struts (thick rectangular) (A) and between the Mirage struts (thinner circular) (B). While recirculation zones were noted in the distal regions of the Absorb (A), there was no reverse flow in the distal region of the Mirage (B).

studies, protrude into the lumen and obstruct flow, resulting in higher ESS at the top of the struts and flow disturbances, recirculation zones, and low ESS in the areas between the struts. On the other hand, the Mirage has a configuration with thinner circular-shaped struts causing lower ESS values at the top of the struts compared to the Absorb scaffold, and causing less flow disruption, resulting in relatively higher ESS in the areas between the struts (Figure 6) ${ }^{15}$.

In addition to strut geometry, luminal surface coverage ratio and maximal coil pitch distances between the coil rings influence the haemodynamic microenvironment in scaffolded segments. The Mirage (45\%) has a significantly higher vessel coverage ratio than the Absorb (27\%). The smaller pitch distance (distance between the helical rings) in the Mirage ( $0.8 \mathrm{~mm}$ vs. $1.0 \mathrm{~mm}$ in Absorb) is likely to increase flow stagnation areas and decrease the ESS in these segments ${ }^{22,23}$. However, as was shown in this analysis, strut thickness was the most important determinant of ESS and thus the ESS was higher in the Mirage in the areas between the struts.

Apart from the differences in the ESS, we have noticed differences in the shear rate in the two scaffold designs. Although the mean shear rate values were similar in Absorb and Mirage, the maximum shear rate values and the percentage of the volume of the scaffolded segment exposed to high shear rate were numerically higher in the Absorb compared to the Mirage, indicating a larger variability of the shear rate values in the Absorb. In addition, we found that the recirculation areas were numerically lower in the thinner-strut Mirage $(125 \mu \mathrm{m})$. This finding is consistent with the results of CFD models which indicate that thinner circular struts lead to a more streamlined flow pattern with less disruption and flow recirculation ${ }^{14}$. Nevertheless, due to the small sample size of the device level analysis, the difference in shear rate and recirculation areas did not reach statistical significance.

The differences in the haemodynamic profile of Absorb and Mirage may have significant clinical implications. The flow disruption noted in Absorb resulted in low ESS that is associated with increased neointima formation ${ }^{3}$ and scaffold restenosis, while the flow stagnation and recirculation zones noted in the areas between the struts may promote thrombus formation, as has been shown in histology studies ${ }^{22,24}$. Finally, high shear rate can trigger activation of platelets and Von Willebrand factor that can promote thrombus formation ${ }^{24}$. This study demonstrated for the first time that in vivo computational modelling is able to identify and quantify haemodynamic indices which may account for the increased incidence of early scaffold thrombosis and cardiovascular events reported in the early Absorb studies, and thus it can be used to test and improve the haemodynamic profile of future bioresorbable scaffold designs.

\section{Limitations}

A significant limitation of the current analysis is that scaffold implantation was performed in healthy coronary arteries. Therefore, it was not possible to examine the implications 
of scaffold underexpansion ${ }^{20}$ or the composition of the underlying plaque on strut embedment which potentially influence the local flow haemodynamics. It would be instructive to assess the stent/scaffold behaviour in atherosclerotic vessels to approximate its actual use. Second, the small number of scaffolds studied did not allow us to assess the impact of scaffold design on shear rate and recirculation zones. Moreover, there were differences in the balloon inflation and post-dilatation pressures between groups. Nevertheless, this did not have an impact on strut protrusion, a paradox that should be attributed to the fact that the scaffolds were implanted in healthy vessels. Finally, there were differences in the lumen areas in the two groups which are likely to affect the ESS values. Nevertheless, these differences were not statistically significant. In addition, in the linear mixed effect analysis, scaffold type was independently associated with the ESS distribution.

\section{Conclusions}

In vivo computational modelling enables assessment of the effect of different scaffold implantation on local haemodynamic patterns. Mirage with circular, thinner struts, with a helicoidal alignment results in a superior ESS pattern compared to the thick rectangular-shaped struts of the Absorb with a zig-zag hoop alignment. This preclinical study is the preamble of the randomised clinical trial comparing Mirage and Absorb in a first-in-man study. Further research is required to examine the potential value of in vivo computational modelling in optimising scaffold configuration and clinical outcomes.

\section{Impact on daily practice}

The Mirage scaffold is a novel BRS and its unique design could provide a better local haemodynamic microenvironment in treated vessels.

\section{Guest Editor}

This paper was guest edited by Lorenz Räber, $\mathrm{MD}, \mathrm{PhD}$; Cardiology Department, Bern University Hospital, Bern, Switzerland.

\section{Funding}

This study was sponsored by Manli Cardiology, Singapore, Singapore.

\section{Conflict of interest statement}

E. Tenekecioglu has received a research grant from TUBITAK (The Scientific Council of Turkey). P. Serruys and Y. Onuma are members of the International Advisory Board of Abbott Vascular. The other authors have no conflicts of interest to declare. The Guest Editor has no conflicts of interest to declare.

\section{References}

1. Wentzel JJ, Krams R, Schuurbiers JC, Oomen JA, Kloet J, van Der Giessen WJ, Serruys PW, Slager CJ. Relationship between neointimal thickness and shear stress after Wallstent implantation in human coronary arteries. Circulation. 2001;103:1740-5.
2. Papafaklis MI, Bourantas CV, Theodorakis PE, Katsouras CS, Naka KK, Fotiadis DI, Michalis LK. The effect of shear stress on neointimal response following sirolimus- and paclitaxel-eluting stent implantation compared with bare-metal stents in humans. JACC Cardiovasc Interv. 2010;3:1181-9.

3. Bourantas CV, Papafaklis MI, Kotsia A, Farooq V, Muramatsu T, Gomez-Lara J, Zhang YJ, Iqbal J, Kalatzis FG, Naka KK, Fotiadis DI, Dorange C, Wang J, Rapoza R, GarciaGarcia HM, Onuma Y, Michalis LK, Serruys PW. Effect of the endothelial shear stress patterns on neointimal proliferation following drug-eluting bioresorbable vascular scaffold implantation: an optical coherence tomography study. JACC Cardiovasc Interv. 2014;7:315-24

4. Papafaklis MI, Bourantas CV, Farooq V, Diletti R, Muramatsu T, Zhang Y, Fotiadis DI, Onuma Y, Garcia Garcia HM, Michalis LK, Serruys PW. In vivo assessment of the three-dimensional haemodynamic micro-environment following drug-eluting bioresorbable vascular scaffold implantation in a human coronary artery: fusion of frequency domain optical coherence tomography and angiography. EuroIntervention. 2013;9:890.

5. Williams PD, Malik N, Kingston PA. Coronary angiography and percutaneous coronary intervention in the porcine model: a practical guide to the procedure. Animal. 2012;6:311-20.

6. National Research Council (US) Committee for the Update of the Guide for the Care and Use of Laboratory Animals. Guide for the care and use of laboratory animals, 8th edition. Washington, DC: National Academies Press; 2011, xxv, 220 p.

7. Ormiston JA, Webber B, Ubod B, Darremont O, Webster MW. An independent bench comparison of two bioresorbable drug-eluting coronary scaffolds (Absorb and DESolve) with a durable metallic drug-eluting stent (ML8/Xpedition). EuroIntervention. 2015;11:60-7.

8. Sotomi Y, Tateishi H, Suwannasom P, Dijkstra J, Eggermont J, Liu S, Tenekecioglu E, Zheng Y, Abdelghani M, Cavalcante R, de Winter RJ, Wykrzykowska JJ, Onuma Y, Serruys PW, Kimura T. Quantitative assessment of the stent/scaffold strut embedment analysis by optical coherence tomography. Int $J$ Cardiovasc Imaging. 2016;32:871-83.

9. Bourantas CV, Papafaklis MI, Lakkas L, Sakellarios A, Onuma Y, Zhang YJ, Muramatsu T, Diletti R, Bizopoulos P, Kalatzis F, Naka KK, Fotiadis DI, Wang J, Garcia Garcia HM, Kimura T, Michalis LK, Serruys PW. Fusion of optical coherence tomographic and angiographic data for more accurate evaluation of the endothelial shear stress patterns and neointimal distribution after bioresorbable scaffold implantation: comparison with intravascular ultrasound-derived reconstructions. Int $J$ Cardiovasc Imaging. 2014;30:485-94.

10. Papafaklis MI, Bourantas CV, Theodorakis PE, Katsouras CS, Fotiadis DI, Michalis LK. Relationship of shear stress with in-stent restenosis: bare metal stenting and the effect of brachytherapy. Int $J$ Cardiol. 2009;134:25-32.

11. Bates D, Mächler M, Bolker BM, Walker SC. Fitting Linear Mixed-Effects Models Using lme4. Journal of Statistical Software. $2015 ; 67: 48$ 
12. Stone PH, Saito S, Takahashi S, Makita Y, Nakamura S, Kawasaki T, Takahashi A, Katsuki T, Nakamura S, Namiki A, Hirohata A, Matsumura T, Yamazaki S, Yokoi H, Tanaka S, Otsuji S, Yoshimachi F, Honye J, Harwood D, Reitman M, Coskun AU, Papafaklis MI, Feldman CL; PREDICTION Investigators. Prediction of progression of coronary artery disease and clinical outcomes using vascular profiling of endothelial shear stress and arterial plaque characteristics: the PREDICTION Study. Circulation. 2012;126:172-81.

13. Jimenez JM, Davies PF. Hemodynamically driven stent strut design. Ann Biomed Eng. 2009;37:1483-94.

14. Pache J, Kastrati A, Mehilli J, Schühlen H, Dotzer F, Hausleiter J, Fleckenstein M, Neumann FJ, Sattelberger U, Schmitt C, Müller M, Dirschinger J, Schömig A. Intracoronary stenting and angiographic results: strut thickness effect on restenosis outcome (ISAR-STEREO-2) trial. J Am Coll Cardiol. 2003;41:1283-8.

15. Joner M, Nakazawa G, Finn AV, Quee SC, Coleman L, Acampado E, Wilson PS, Skorija K, Cheng Q, Xu X, Gold HK, Kolodgie FD, Virmani R. Endothelial cell recovery between comparator polymer-based drug-eluting stents. J Am Coll Cardiol. 2008;52:333-42.

16. Pache J, Dibra A, Mehilli J, Dirschinger J, Schomig A, Kastrati A. Drug-eluting stents compared with thin-strut bare stents for the reduction of restenosis: a prospective, randomized trial. Eur Heart J. 2005;26:1262-8.

17. Capodanno D, Gori T, Nef H, Latib A, Mehilli J, Lesiak M, Caramanno G, Naber C, Di Mario C, Colombo A, Capranzano P, Wiebe J, Araszkiewicz A, Geraci S, Pyxaras S, Mattesini A, Naganuma T, Munzel T, Tamburino C. Percutaneous coronary intervention with everolimus-eluting bioresorbable vascular scaffolds in routine clinical practice: early and midterm outcomes from the European multicentre GHOST-EU registry. EuroIntervention. 2015;10:1144-53.

18. Ishibashi Y, Onuma Y, Muramatsu T, Nakatani S, Iqbal J, Garcia-Garcia HM, Bartorelli AL, Whitbourn R, Abizaid A, Serruys PW; ABSORB EXTEND Investigators. Lessons learned from acute and late scaffold failures in the ABSORB EXTEND trial. EuroIntervention. 2014;10:449-57.

19. Gomez-Lara J, Radu M, Brugaletta S, Farooq V, Diletti R, Onuma Y, Windecker S, Thuesen L, McClean D, Koolen J, Whitbourn R, Dudek D, Smits PC, Regar E, Veldhof S, Rapoza R, Ormiston JA, Garcia-Garcia HM, Serruys PW. Serial analysis of the malapposed and uncovered struts of the new generation of everolimus-eluting bioresorbable scaffold with optical coherence tomography. JACC Cardiovasc Interv. 2011;4:992-1001.

20. Foin N, Lee R, Bourantas C, Mattesini A, Soh N, Lim JE, Torii R, Ng J, Liang LH, Caiazzo G, Fabris E, Kilic D, Onuma Y, Low AF, Nijjer S, Sen S, Petraco R, Al Lamee R, Davies JE, Di Mario C, Wong P, Serruys PW. Bioresorbable vascular scaffold radial expansion and conformation compared to a metallic platform: insights from in vitro expansion in a coronary artery lesion model. EuroIntervention. 2016;12:834-44.
21. Wentzel JJ, Whelan DM, van der Giessen WJ, van Beusekom HM, Andhyiswara I, Serruys PW, Slager CJ, Krams R. Coronary stent implantation changes 3-D vessel geometry and 3-D shear stress distribution. J Biomech. 2000;33:1287-95.

22. Berry JL, Santamarina A, Moore JE Jr, Roychowdhury S, Routh WD. Experimental and computational flow evaluation of coronary stents. Ann Biomed Eng. 2000;28:386-98.

23. Seo T, Schachter LG, Barakat AI. Computational study of fluid mechanical disturbance induced by endovascular stents. Ann Biomed Eng. 2005;33:444-56.

24. Kolandaivelu K, Swaminathan R, Gibson WJ, Kolachalama VB, Nguyen-Ehrenreich KL, Giddings VL, Coleman L, Wong GK, Edelman ER. Stent thrombogenicity early in high-risk interventional settings is driven by stent design and deployment and protected by polymer-drug coatings. Circulation. 2011;123: 1400-9.

25. Serruys PW, Onuma Y, Ormiston JA, de Bruyne B, Regar E, Dudek D, Thuesen L, Smits PC, Chevalier B, McClean D, Koolen J, Windecker S, Whitbourn R, Meredith I, Dorange C, Veldhof S, Miquel-Hebert K, Rapoza R, Garcia-Garcia HM. Evaluation of the second generation of a bioresorbable everolimus drug-eluting vascular scaffold for treatment of de novo coronary artery stenosis: six-month clinical and imaging outcomes. Circulation. 2010;122: 2301-12.

26. Feldman CL, Ilegbusi OJ, Hu Z, Nesto R, Waxman S, Stone PH. Determination of in vivo velocity and endothelial shear stress patterns with phasic flow in human coronary arteries: a methodology to predict progression of coronary atherosclerosis. $\mathrm{Am}$ Heart J. 2002;143:931-9.

27. Tenekecioglu E, Torii R, Bourantas C, Crake T, Zeng Y, Sotomi Y, Onuma Y, Yilmaz M, Santoso T, Serruys PW. Preclinical assessment of the endothelial shear stress in porcine-based models following implantation of two different bioresorbable scaffolds: effect of scaffold design on the local haemodynamic micro-environment. EuroIntervention. 2016;12:1296.

28. Sakamoto S, Takahashi S, Coskun AU, Papafaklis MI, Takahashi A, Saito S, Stone PH, Feldman CL. Relation of distribution of coronary blood flow volume to coronary artery dominance. Am J Cardiol. 2013;111:1420-4.

\section{Supplementary data}

Supplementary Appendix. Methods.

Supplementary Table 1 . Inventory of scaffolds and implantation parameters.

Supplementary Table 2. Percentage of recirculation area per scaffolded surface in each scaffold and in the two scaffold groups.

\footnotetext{
The supplementary data are published online at:

http://www.pcronline.com/

eurointervention/126th_issue/210
} 


\section{Supplementary data}

\section{Supplementary Appendix. Methods}

\section{Protrusion analyses}

Since the struts of Mirage scaffolds are not translucent, the delineation of the abluminal strut border in the Mirage cannot be performed unequivocally. Due to this fact, only protrusion analyses were implemented. We used the inter-strut automatic detection of lumen contours as an interpolated boundary to quantify the protrusion of the struts. The luminal borders of both scaffold types and each Absorb BVS strut were automatically detected by the software. In Absorb and Mirage scaffolds, struts located at a side branch ostium were excluded from the protrusion analysis. In total, 6,207 struts were studied in both types of scaffold. The analyses were performed at cross-section level $(n=1,075)$ and at device level $(n=11)$. Protrusion percentages and protrusion distances were estimated.

\section{Coronary artery reconstruction}

In brief, the angiographic and OCT data were reviewed to identify the scaffolded segment and the anatomical landmarks (i.e., side branches) most proximal and distal to the scaffolded segment that were visible in both coronary angiography and OCT examination. The proximal and distal anatomical landmarks were used to define the segment of interest. In this segment, an observer analysed the OCT frames at every $100 \mu \mathrm{m}$ interval in the scaffolded segments and at every $400 \mu \mathrm{m}$ interval in the non-scaffolded segments. In the scaffolded segment an observer delineated the lumen area defined by the lumen border and the flow area defined by the adluminal side of the struts and by the lumen border in the areas between the struts. Moreover, in the non-scaffolded segment the observer annotated the lumen area (which is also the flow area), defined by the lumen border (Figure 2A, Figure 2B) [25]. 
Two post-procedural end-diastolic angiographic images with at least $>30^{\circ}$ angle difference that were acquired with the table in the isocentre and which portrayed the segment of interest with minimal foreshortening were selected. In these images the lumen borders were detected in the segment of interest and used to extract the luminal centreline that was then used to define the 3D luminal centreline [9]. The borders detected in the OCT images were then placed perpendicularly onto the luminal centreline. Side branches seen in both OCT and Xray angiography images were used to define the absolute orientation of the OCT frames [9]. Two reconstructions were performed for each scaffold and proximal/distal non-scaffolded segment, one from the flow area borders (flow model) in both scaffolded and non-scaffolded segments and the other from the flow area in the non-scaffolded segment and the lumen area in the scaffolded segment (reference model) (Figure 2A, Figure 2B). For each point detected in the flow model, a corresponding point was identified in the reference model - defined as the closest point from the reference model - and their distance was estimated. Based on this distance, the points of the flow model in the scaffolded segment were classified into two groups: 1) points corresponding to apposed struts (points with Euclidian distance $>2 / 3$ of the strut thickness, i.e., $104 \mu \mathrm{m}$ for Absorb and $83 \mu \mathrm{m}$ for Mirage), 2) points corresponding to areas between struts (points with Euclidian distance $<1 / 3$ of the strut thickness, i.e., $52 \mu \mathrm{m}$ for Absorb and $42 \mu \mathrm{m}$ for Mirage), and 3) unclassified points (points with Euclidian distance $>1 / 3$ and $<2 / 3$ of the strut thickness, i.e., 52-104 $\mu \mathrm{m}$ for Absorb and 42-83 $\mu \mathrm{m}$ for Mirage) which correspond to the edges of apposed struts or to embedded struts. After the classification of the points, the points were described as “Top” which corresponds to the top of the struts, "Base” which refers to the luminal surface between the struts, and "Intermediate” which refers to the edges of the struts. 
To assess the effect of different scaffold designs on the local haemodynamic microenvironment, the mesh density around the scaffold struts and within the boundary layer of the flow field between the struts was increased to have an average element edge of $30 \mu \mathrm{m}$ (equal to $1 / 4$ of the strut thickness of the scaffold strut). Blood was assumed to be a homogeneous, Newtonian fluid with a viscosity of 0.0035 Pa.s and a density of 1,050 kg/m³. A steady flow profile was simulated at the inflow of the 3D models, as it has been shown that there are no significant differences between the ESS estimated in pulsatile and steady flow simulation [26,27]. Blood flow for each reconstruction was estimated by measuring, in the two angiographic projections, the number of frames required for the contrast agent to pass from the inlet to the outlet of the reconstructed segment, the volume of the reconstructed segment and the cine frame rate $[1,28]$. To avoid the effect of the boundary conditions on the ESS distribution in the scaffolded segments (i.e., an increased blood velocity at the inflow would result in higher ESS distribution in the scaffolded segment) and thus have more accurate evaluation of the implications of scaffold design on the local haemodynamic forces, we normalised the ESS values so that in the native vessel the mean ESS was 1.35 Pa which corresponds to the average moderate ESS reported in the PREDICTION study [12]. This normalisation allowed us to compare the effect of the two scaffold types on the ESS, as in both types the native segments proximal and distal to the scaffolds were exposed to the same haemodynamic environment. The arterial wall was considered to be rigid. No-slip conditions were imposed at the scaffold surface. At the outlet of the model, zero pressure conditions were imposed. ESS at the baseline luminal surface was calculated as the product of blood viscosity and the gradient of blood velocity at the wall. The ESS was measured at the top of the strut and at the luminal surface between the struts in the scaffolded segment and along the axial direction per $0.2 \mathrm{~mm}$ interval with the use of an in-house algorithm (Figure 3). In addition, the shear rate in the scaffolded segment was calculated and the maximum shear rate, 
mean shear rate, percentage of the volume of the scaffolded vessel segment exposed to shear rate $>500 \mathrm{~s}^{-1}$ and percentage of the volume of the scaffolded vessel segment exposed to shear rate $>1,000 \mathrm{~s}^{-1}$ were measured in Absorb and Mirage. The recirculation zones in the vicinity of the struts were quantified based on the direction of the ESS vector and the centreline vector. Areas where the ESS vector had opposite direction to the centreline vector were considered to be exposed to recirculation zones. 
Supplementary Table 1. Inventory of scaffolds and implantation parameters.

\begin{tabular}{|c|c|c|c|c|c|c|c|c|c|}
\hline Scaffold & Animal & Vessel & $\begin{array}{c}\text { Scaffolded vessel } \\
\text { segment }\end{array}$ & $\begin{array}{l}\text { Scaffold } \\
\text { size } \\
(\mathrm{mm})\end{array}$ & $\begin{array}{c}\text { Deployment } \\
\text { balloon } \\
\text { pressure } \\
\text { (atm) }\end{array}$ & $\begin{array}{l}\text { Post- } \\
\text { dilatation } \\
\text { balloon } \\
\text { inflation } \\
\text { pressure } \\
\text { (atm) }\end{array}$ & $\begin{array}{l}\text { Expected maximal } \\
\text { diameter of post- } \\
\text { dilatation balloon at } \\
\text { maximum inflation } \\
\text { pressure }(\mathrm{mm})\end{array}$ & $\begin{array}{l}\text { Post-dilatation } \\
\text { balloon diameter at } \\
\text { its maximum } \\
\text { inflation pressure } \\
\text { during the procedure } \\
(\mathrm{mm})\end{array}$ & $\begin{array}{l}\text { Diameter of } \\
\text { the scaffold } \\
\text { after } \\
\text { implantation } \\
\text { (in vitro) } \\
\text { (mm) }\end{array}$ \\
\hline Absorb BVS -1 & B & RCA & Mid vessel & $3.0 \times 18$ & 7 & 7 & 3.5 & 3.32 & 3.0 \\
\hline Absorb BVS -2 & $\mathrm{A}$ & $\mathrm{LCx}$ & Mid vessel & $3.0 \times 18$ & 7 & 8 & 3.5 & 3.36 & 3.0 \\
\hline Absorb BVS -3 & C & LCx & Proximal vessel & $3.0 \times 18$ & 7 & 8 & 3.5 & 3.32 & 3.0 \\
\hline Absorb BVS -4 & $\mathrm{D}$ & LAD & Mid vessel & $3.0 \times 18$ & 7 & 10 & 3.5 & 3.36 & 3.0 \\
\hline Absorb BVS -5 & $\mathrm{F}$ & RCA & Mid vessel & $3.0 \times 15$ & 7 & 14 & 3.5 & 3.56 & 3.3 \\
\hline Absorb BVS -6 & $E$ & LCx & Mid vessel & $3.0 \times 18$ & 7 & 7 & 3.5 & 3.32 & 3.0 \\
\hline Mirage BRMS-1 & $B$ & $\mathrm{LCx}$ & Mid vessel & $2.75 \times 13$ & 6 & 16 & 3.0 & 3.08 & 3.0 \\
\hline Mirage BRMS-2 & $B$ & LAD & Proximal vessel & $2.75 \times 13$ & 6 & 12 & 2.75 & 2.74 & 2.6 \\
\hline Mirage BRMS-3 & $E$ & RCA & Mid vessel & $3.0 \times 15$ & 10 & 18 & 3.5 & 3.63 & 3.3 \\
\hline Mirage BRMS-4 & G & LAD & Proximal vessel & $2.75 \times 13$ & 16 & 18 & 3.0 & 3.08 & 3.0 \\
\hline Mirage BRMS-5 & $\mathrm{H}$ & RCA & Mid vessel & $3.0 \times 15$ & 6 & 10 & 3.0 & 2.84 & 3.0 \\
\hline
\end{tabular}


Supplementary Table 2. Percentage of recirculation area per scaffolded surface in each scaffold and in the two scaffold groups.

\begin{tabular}{|l|c|c|}
\hline Scaffold & $\begin{array}{c}\text { Recirculation area per } \\
\text { scaffolded vessel surface } \\
\text { area (\%) }\end{array}$ & \multirow{2}{*}{ Mean \pm SD } \\
\hline Absorb BVS-1 & 3.50 & \\
\hline Absorb BVS-2 & 2.72 & \multirow{2}{*}{$3.26 \pm 2.07$} \\
\hline Absorb BVS-3 & 0.43 \\
\hline Absorb BVS-4 & 6.03 \\
\hline Absorb BVS-5 & 1.80 \\
\hline Absorb BVS-6 & 5.10 \\
\hline Mirage BRMS-1 & 2.00 \\
\hline Mirage BRMS-2 & 2.81 \\
\hline Mirage BRMS-3 & 0.87 \\
\hline Mirage BRMS-4 & 3.93 \\
\hline Mirage BRMS-5 & 3.98 \\
\hline
\end{tabular}

${ }^{+}$Comparison between Absorb BVS and Mirage BRMS $(p=0.87)$. 